\title{
Open Learning Approach with Remote Experiments: OLAREX Project
}

\author{
http://dx.doi.org/10.3991/ijep.v3i4.2871 \\ J. García-Zubía ${ }^{1}$, I. Angulo ${ }^{1}$, O. Dziabenko ${ }^{2}$, P. Orduña ${ }^{2}$ \\ ${ }^{1}$ University of Deusto, Bilbao, Spain \\ 2 Deusto Institute of Technology - DeustoTech, Bilbao, Spain
}

\begin{abstract}
The project's primary target groups are the European secondary schools. More specifically: secondary school and university teachers, students and managers of schools, museum employees and their visitors, and other STEM education providers. The main goal of the OLAREX project is to offer the providers of formal and non-formal education an efficient way to improve their e-didactic and digital competences. For this purpose a training program is created with using ICT-based learning materials, remote laboratories, and e-learning methodologies
\end{abstract}

Index Terms-remote labs, K-12 education, distance education

\section{INTRODUCTION}

There is a widespread consensus in Europe that industry requires well educated STEM (Science, Technology, Engineering and Mathematics) graduates [1]. Since students' motivation to learn depends upon the knowledge and skills of the teachers, teachers should have access to high quality and real-life-based resources to build their competence, to support student's improvement, to familiarize with up-to-date research/development and industrial needs in STEM. Therefore, the knowledge exchange between school and industry through the university expertise should be established or improved.

Society needs a new vision on quality and effectiveness from education and training systems to attract students to the STEM disciplines. One approach is to build up-to-date e-didactic and technology competences for professionals who pedagogically support formal and non-formal learning. Another approach is to provide the students with multimedia, interactive e-learning courses including experimental laboratories. The fundamental benefit of experimenting is motivating students into innovation and creativity. However, laboratory equipment is expensive and its maintenance is complicated. Remote laboratories reduce the costs significantly, makes lab experiments available almost at any time and everywhere, personalizing the learning pathways. Updating curricula in secondary education study programs by including new e-learning approaches is one of the key issues in the modernization and enhancing of STEM study. One of the objectives of curriculum design is to ensure the quality of curriculum parameters, as well as creating learning situations that engage students in learning and assisting them in measuring their progress or achievement. Therefore, learning environment and opportunities, pedagogical support, and methodologies that will encourage STEM learners have to be improved by updating and/or establishing new curricula of studies, introducing new practical experiences for students, linking to the innovative elements in ICT use -integration remote and media experiments.

Observing the decreasing tendency in the interest in STEM studies and understanding the demand for well educated individuals for the EU industry during next 10 years, the consortium decided to reconsider new strategies in the STEM educational field:

- to evaluate the curriculum needs in terms of school/university/industry requirements;

- to develop e-didactic competences for STEM teachers and provide them with access to remote laboratories and remote experimentation places to deepen their knowledge and skills;

- $\quad$ to engage the non-formal educators - museum exhibition designers - in technology/engineering/ remote-experiments activities by improving their knowledge and skills in these fields;

- to motivate students using up-to-date e-learning material with remote experiments, museum provocative activities, and linkage to the enterprises.

This paper will describe the objectives, the outcomes and challenges of the OLAREX project.

\section{OLAREX OBJECTIVES AND OUTCOMES}

The project involves 8 partners: University of Deusto (Spain), P. Andrés Urdaneta School (Spain), Europa Media Non-Profit Ltd. (Hungary), Carinthia University of Applied Sciences (Austria), BG/BRG Peraustraße (Austria), National Polytechnic Museum (Bulgary), Vytautas Magnus University (Lithuania), Radomska Szkoła Wyższa (Polland), and its aims are to enhance and modernize STEM curricula, foster student's creativity and motivation, and develop professional e-didactic and technology competences and skills. To accomplish these aims, the following objectives are to be reached:

- Elaborate the needs analysis report.

- Develop multimedia interactive e-learning contents: At least 6 learning modules with practical tasks and remote experiments will be developed and implemented into the interactive multimedia e-materials by using the state-of-theart ICT technology.

- $\quad$ Provide the external tools and social networking (Facebook, TeacherTube, ...). 
- Improve e-didactic competences with training courses and remote labs for teachers, developers and museum employees

- Survey project impact on end-users satisfaction of the remote laboratory experience.

At present there are some results as the website [2], the Moodle platform for the training courses [3], the Facebook page [4] and the description of the modules to be implemented by the project.

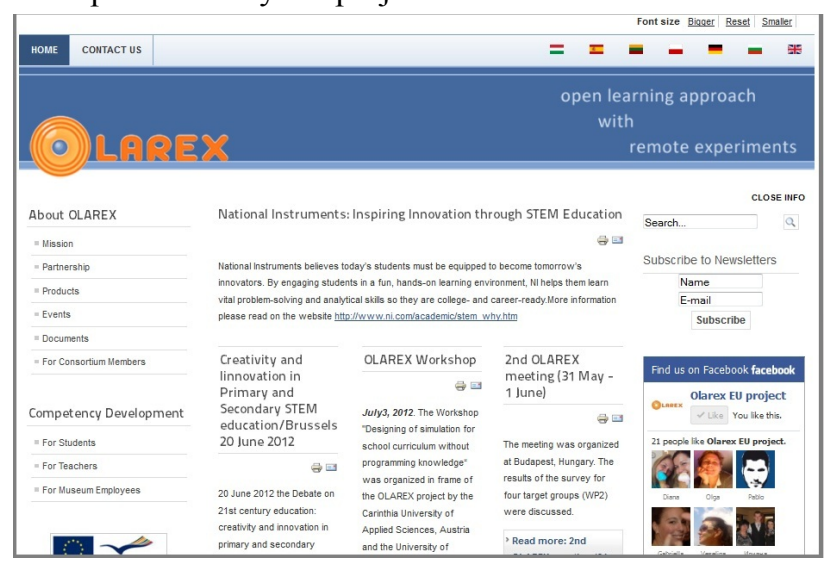

Figure 1. OLAREX website

Fig. 2 shows the structure of the modules that are being implemented by the universities and the schools.

Topics of the six learning modules with remote experiments were chosen by secondary school teachers and their management by means of a e-survey. These are:

- Black body radiation of common light sources (Physics /Optics)

- Farm Experiment: From an egg to a baby chick, step by step (Biology)

- Working as a computer - Logic gates (Technology \& Mathematics)

- Analog circuits measurements (Physics)

- How does the current flow? (Physics)

- $\quad$ Easy Java Simulation for Phys\&Sports

Most of the courses are already available in draft version. In the period between January and May 2013 all courses will be tested in an international setting with participants from the secondary schools of the consortium countries. The pilot training courses will offer the possibility to around 100 secondary school teachers to acquire ICT competence through contemporary instruments.

Average learning time of a training course is at least 10 hours: 4 hours for theory, 2 hours for execution of exercises/tests/experiments and 4 hours for the final project. The final project includes curriculum implementation of learning modules developed and presented by OLAREX team, and knowledge and skills achieved over training. After the training the participators will:

(1) improve e-didactic competences;

(2) know the basic theory of remote experiments, how to access to remote laboratory;

(3) be able to create new e-learning materials, courses, and remote experiments.

\section{OLAREX MODULES DESCRIPTION}

\section{A. Black body radiation of common light sources}

The project is an attempt to establish a remote controlled set-up allowing the analysis of the black-body radiation of different sources such as light bulbs or heated surfaces. The Stephan-Boltzmann Law will serve as a basis for this analysis. For this purpose an existing set-up used for teaching purposes will be adopted.

This set-up comprises of a source of radiation, a termopar as well a set of several LabVIEW controlled infrared detectors and the electronics driving the radiating sources. In the present project two goals are aimed at:

- Realization of a remote control of the radiation sources, hence allowing for setting the radiating power and for changing of the radiation source by also implementing, for example by using light bulbs.

- Implementation of a linear drive belt system for moving the detection systems along a linear path in order to account for the distance dependence of the radiation power.

The remote laboratory will be developed using LabVIEW from National Instruments and integrated in the Online Labs Network from Carinthia University of Applied Sciences (CUAS) Villach, Austria.

The overall solution will be integrated by students from Bachelor and Master Programs specializing in Mechatronics and Remote Systems and the module is designed for the students of secondary schools in the bracket between 13 and 18 years. The experiment will be remotely accessible 24 hours per day and 7 days a week.

\section{B. Farm Experiment: From an egg to a baby chick, step by step}

This learning module addresses Biology. The main objectives of this module are :

- $\quad$ to study the process of embryos growing in eggs until the hatching of baby chicks;

- to apply the ICT to obtain images and to collect data from this process.

The incubator will be placed at the Baratze Farm (Bizkaia, Spain) and it will be remotely connected to WebLab-Deusto. The Baratze Farm will support interacting with the real world and provide an environmental approach of the learning materials. Using the interface of WebLab-Deusto [5] the secondary school teachers and their students can modify the parameters and variables of experiments such as heating and lightening. Additionally, the students will take different measurements such as height of the eggs, length, temperature, etc..., which will show them how the embryo develops. They will remotely observe the embryo in real time by ovoscope and record its image with a camera. Since most chicken eggs will hatch within 22 days, the learning module should run during this period. The received results and images will be described and identified by the students. The measurements will be stored in charts. Basic statistical mathematical methods will be used for analyzing the results. During this activity students will learn: 
- $\quad$ application of remote experiments in different concepts, basic knowledge and skills to work with remote equipment, fundamental features of remote laboratories, difference between remote and virtual laboratories;

- organization of scientific documentation and understanding the real experiment as a significant part of scientific work;

- basic statistical methods for scientific analysis of received data;

- doing teamwork: sharing tasks, knowledge, skills, and information.

The module aims at the students of secondary schools in the age bracket between 11 and 18 years depending on the educator's assignments.

\section{Working as a computer-Logic gates}

This module is related to Technology and Mathematics subjects of secondary school curricula. During this activity concepts from the Boolean algebra, which is a basis of Mathematical knowledge and Digital Electronics, will be studied. The authors of this module see it as a transition bridge between secondary school and University curriculum. It addresses secondary school students of 16-18 years or freshmen at University. The learning module includes the following objectives:

- different ways of representing a signal (binary, hexadecimal,..), logic variables, Boolean functions and instruments for Boolean algebra application;

- mathematical logic, different types of gates: AND, OR, NOT, creation and simplification of logic circuits.

- The module includes a broad practical part based on the experiments of WebLab-Deusto and in the Boole-Deusto software tool.

The practice helps students in the understanding of the function of remote laboratories and experiments implemented there, usage of logic variables and circuits, applying them in computer science, and the benefits of applying Boolean algebra to solve specific scientific problems.

\section{Analogue circuits measurements}

On the basis of VISIR (Virtual Instrument Systems In Reality) [6] the set of remote experiments will be designed. The set includes topics such as:

- $\quad$ serial circuits with two or more resistors;

- parallel circuits with two or more resistors;

- mixed circuits (serial and parallel with a couple of resistors);

- diodes and multiplier (Vorwiderstand in German);

- LED - light-emitting diode (Kennlinien in German).

The main objectives of the module are to provide basic knowledge and skills to work with remote equipment, fundamental features of remote laboratories, difference between remote and virtual laboratories as well as experience in analogue circuits measurements.
The module aims at the students of secondary schools of ages between 13 and 18 years.

\section{E. How does the current flow?}

This module relates to Physics subjects allowing teaching electric circuits in a web-based, interactive format with remote experiments. These experiments will be created on the equipment of VISIR remote laboratory. The learning module helps students to enforce understanding of basic concepts of Electricity and use of the Ohm's Law. While using VISIR remote laboratory students will alter the resistance or the voltage and observe its effect upon the current. After completion of this module students will know:

- basic knowledge and skills to work with remote equipment, fundamental features of remote laboratories, difference between remote and virtual laboratories;

- how the current flows;

- how to use Ohm's Law to demonstrate the relation between resistance, voltage, and current. Apart from that, a measure of resistances and a difference between the analytic and the experimental measurements will be investigated. All circuits have generators and we are going to apply them in different ways;

- the last part of the module will be focused on the topic of the AC currents' characteristics and features, and capacitors. At this point, they will review concepts of generators and the use of an oscilloscope.

The module aims at secondary school students in the age bracket between 13 and 18 years.

\section{F. Easy Java Simulation for Phys\&Sports}

Physics is a subject, in which students can learn a lot about theory, if they can interact with simulations, which are developed especially for this purpose.

The main objectives of the module are:

- learning about mathematical modeling of physical objects or processes in sports;

- test an online simulation with different parameters;

- $\quad$ interpret the results and write a report.

In order to successfully complete the assignments of this module the students should have basic knowledge in physics, mathematics and in the application of mathematical models.

The module is designed in two parts - theory and practice:

Theory: Providing basic information about systems, models and simulations; elementary information about the Easy Java Simulation Tool and its application for building simulations for secondary school Physics curriculum;

Practice: Designing and developing a simulation to demonstrate the connection between physics problems and sport. This simulation will be developed by the students under the guidance of their teachers to be used 


\section{SPECIAL FOCUS PAPER \\ OPEN LEARNING APPROACH WITH REMOTE EXPERIMENTS: OLAREX PROJECT}

by other students from their own schools and other schools of the consortium countries.

In order to motivate students the topic for the final student project is left open. The students will choose the topic which is the most interesting for them. For these simulations, different possibilities -how to use it in different learning environments such as off-site, blended learning etc.- will be described. It is planned to exchange the results and final simulation projects with other school partners of the project.

The module aims at secondary school students in the age between 15 and 18 years.

\section{HOW DOES THE CURRENT FLOW? MODUL IN DETAIL}

The teaching/learning approach in this scenario combines mathematical models, simulations, and real and remote experiments. The combination of these different tools will improve the teaching/learning process of the student, but it should be done carefully.

In general, the teacher shows or demonstrates the students a mathematical model, after he uses it with some examples, and the last step is for the students to use the mathematical model with new exercises.

For example, two or more resistors connected in serial mode are equal to a resistor whose value is the addition of the original resistors:

$\mathrm{Rt}=\mathrm{R} 1+\mathrm{R} 2+\mathrm{R} 3 \ldots \mathrm{Rn}=1 \mathrm{~K}+1 \mathrm{~K}+1 \mathrm{~K}=3 \mathrm{~K}$

If the connection is in parallell, the mathematical model is:

$$
\frac{1}{R t}=\frac{1}{R 1}+\frac{1}{R 2}+\frac{1}{R 3}+\ldots+\frac{1}{R n}
$$

Using the VISIR remote lab, the student/teacher can test with an experiment the validity of the mathematical model. Of course that the mathematical model is true or valid and then the student will believe the teacher, but with the experiment he/she will reinforce his/her confidence in the model.

After the experiment, the student can analyze the differences between the model and reality, and also he can discuss about the measurement and the error absolute and relative-.

In this case the OLAREX module asks the student to fill the Table 1.

The next step of the module is to follow the same approach with Ohm's Law. The student will analyze different circuits using the Ohm's Law $-\mathrm{V}=\mathrm{I} \times \mathrm{R}-$ and after this, and using VISIR, he/she will experiment with the same circuits in the remote lab to measure the signals involved: voltage and current with DC power. The final conclusion of student should be: "the Ohm's Law is true" (at least for the tested circuits) (see Table 2).

At this moment, the student has two different tools: the mathematical model to design and the experiment to analyze. The Falstad simulation tool [7] is in the middle of the two approaches: it is an experiment, but it is not true, it is simulated. The main advantages of a simulator are the power and the availability. A simulation looks like an experiment, but the values looks like a mathematical model. The student should obtain with Falstad the same results than with VISIR. After this, the student must test if Ohm`s Law is true for AC power (alternating current).

In the last step — the final project—, the student must analyze using VISIR and Falstad a RC circuit using different values of resistors, capacitors and input signals (frequency). With the results obtained he/she should be able to obtain first a quantitative model of what happens in a RC circuit, and then he/she should obtain a mathematical model for the behavior of the circuit. The student can search for information in the web, books, etc. to obtain the mathematical model, but he/she must test it with the experiments and results obtained with the VISIR remote lab and with the Falstad simulator.

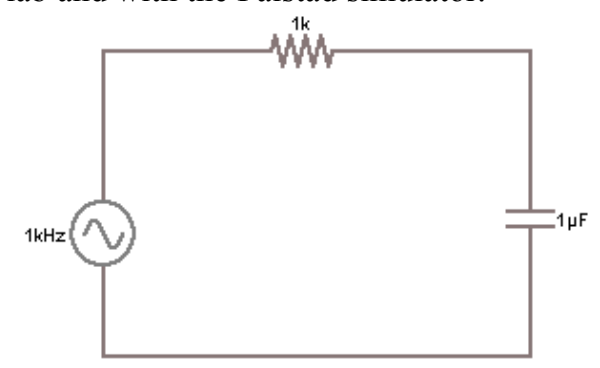

Figure 2. RC circuit
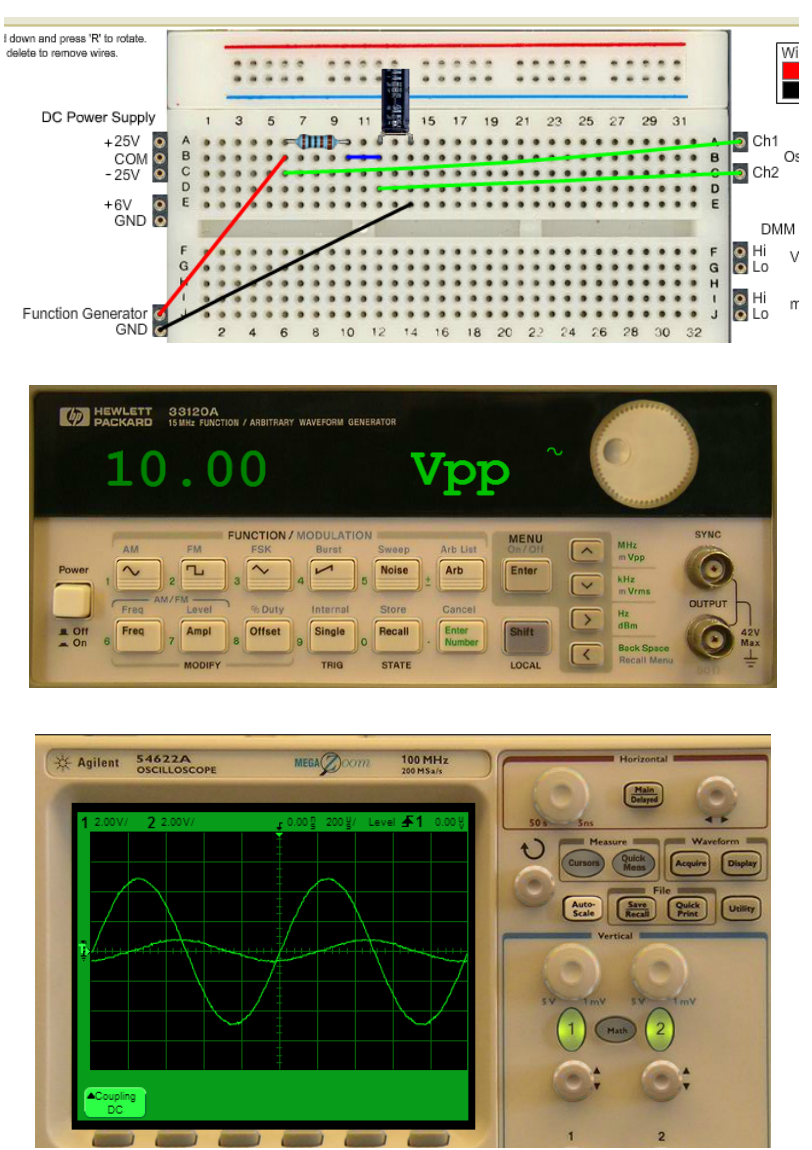

Figure 3. VISIR experiment: circuit, function generator and oscilloscope 
SPECIAL FOCUS PAPER

OPEN LEARNING APPROACH WITH REMOTE EXPERIMENTS: OLAREX PROJECT

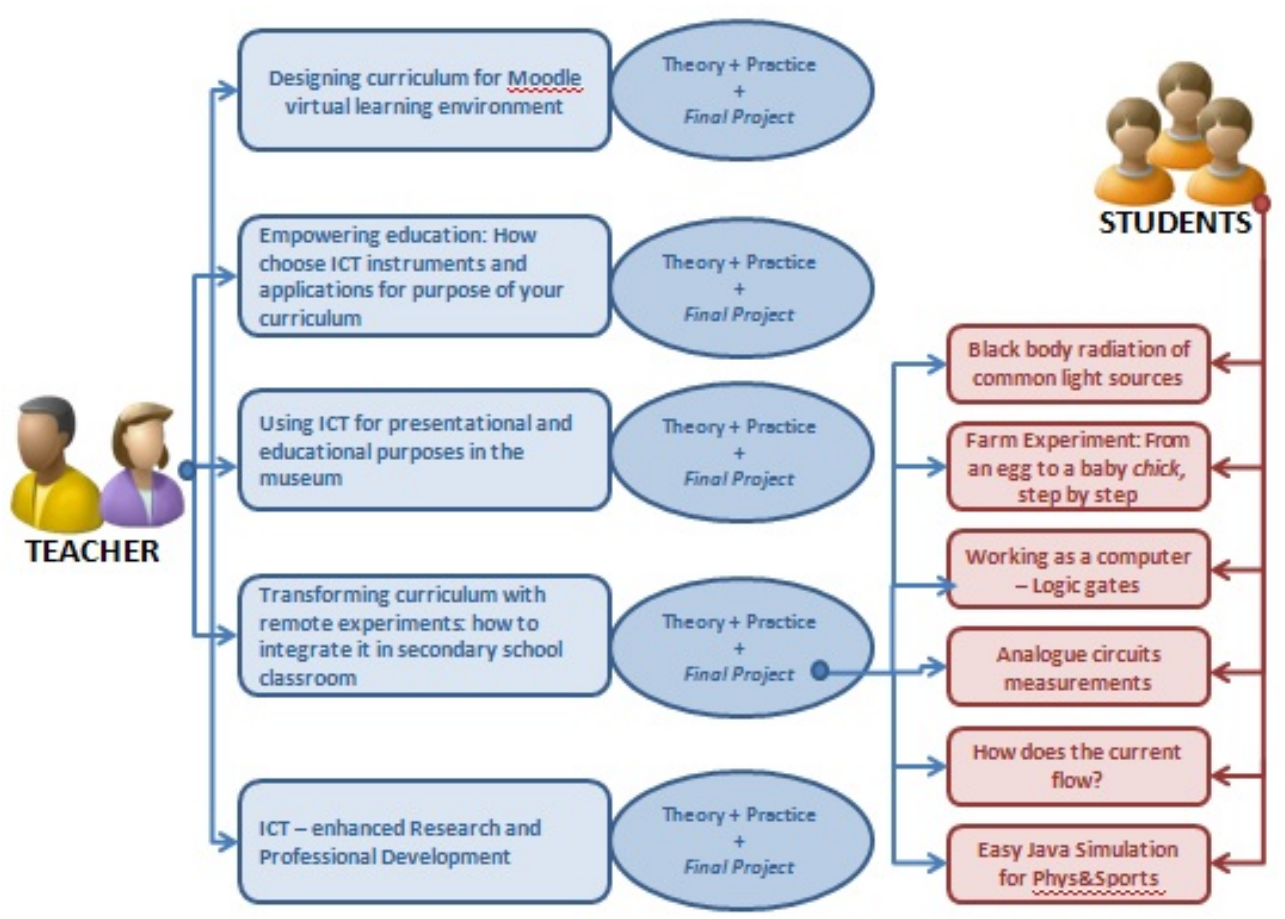

Figure 4. Training modules: objectives (left) - structure (middle) - modules (right)

TABLE I. VISIR EXPERIMENTS AND MATHEMATICAL MODEL FOR CIRCUITS WITH RESISTORS

\begin{tabular}{|c|c|c|c|}
\hline Experiment 1 & Experiment 2 & Experiment 3 & Experiment n \\
\hline Circuit & Circuit & $-\Gamma_{-1}^{1}$ & $10 \mathrm{~W}$ \\
\hline $\begin{array}{l}\text { Model results } \\
\mathrm{RT}=1 \mathrm{~K}+1 \mathrm{~K}=2 \mathrm{~K} \Omega\end{array}$ & $\begin{array}{l}\text { Model results } \\
\mathrm{RT}=10 \mathrm{~K}+10 \mathrm{~K}=20 \mathrm{~K} \Omega\end{array}$ & $\begin{array}{l}\text { Model results } \\
\frac{1}{R t}=\frac{1}{1}+\frac{1}{1} \\
R t=1 / 2 K \Omega=0,5 K \Omega\end{array}$ & $\begin{array}{l}\text { Model results } \\
\text { To be calculated by the student }\end{array}$ \\
\hline 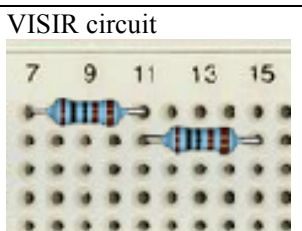 & $\begin{array}{l}\text { VISIR circuit } \\
\\
\text { AnItas }\end{array}$ & VISIR circuit & $\begin{array}{l}\text { VISIR circuit } \\
\text { To be created by the student }\end{array}$ \\
\hline 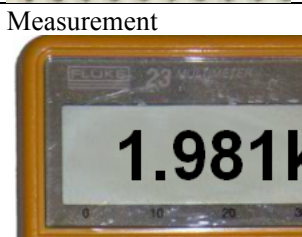 & Measurement & Measurement & $\begin{array}{l}\text { Measurement } \\
\text { To be measured by the student }\end{array}$ \\
\hline $\begin{array}{l}\text { Error } \\
\text { error }=0,019 \mathrm{~K} \Omega \\
\text { error } \%=0,95 \%\end{array}$ & $\begin{array}{l}\text { Error } \\
\text { error }=0,42 \mathrm{~K} \Omega \\
\text { error } \%=2,1 \%\end{array}$ & $\begin{array}{l}\text { Error } \\
\text { error }=-5,5 \Omega \\
\text { error } \%=-1,1 \%\end{array}$ & $\begin{array}{l}\text { Error } \\
\text { To be calculated by the student }\end{array}$ \\
\hline
\end{tabular}


SPECIAL FOCUS PAPER

OPEN LEARNING APPROACH WITH REMOTE EXPERIMENTS: OLAREX PROJECT

TABLE II. VISIR EXPERIMENTS, FALSTAD SimUlATIONS AND MATHEMATICAL MODEL FOR MEASURING VOLTAGE AND CURRENT IN CiRCUITS WITH RESISTORS

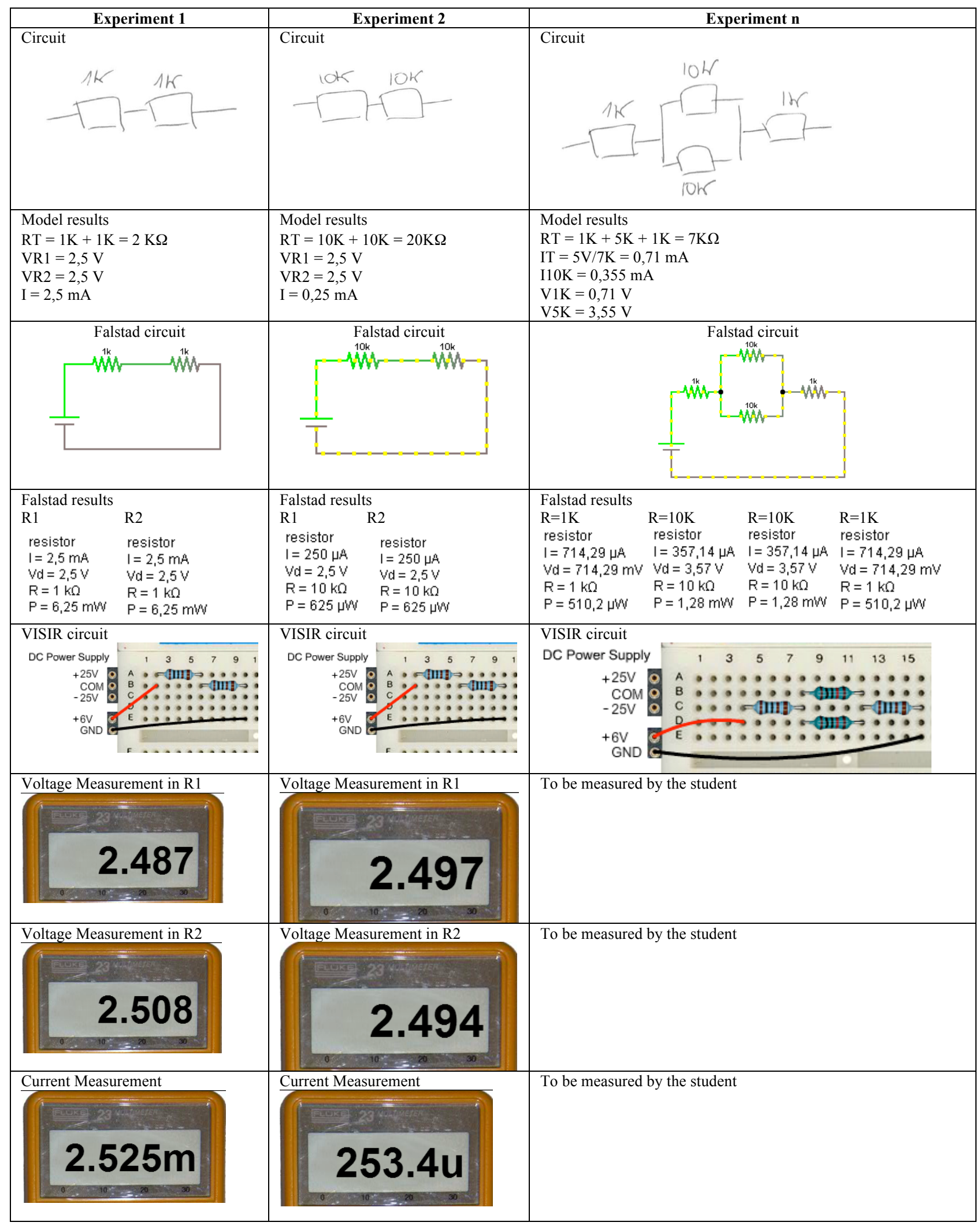


SPECIAL FOCUS PAPER

OPEN LEARNING APPROACH WITH REMOTE EXPERIMENTS: OLAREX PROJECT

TABLE III. VISIR EXPERIMENTS AND MATHEMATICAL MODEL FOR RC CIRCUITS AND AC POWER

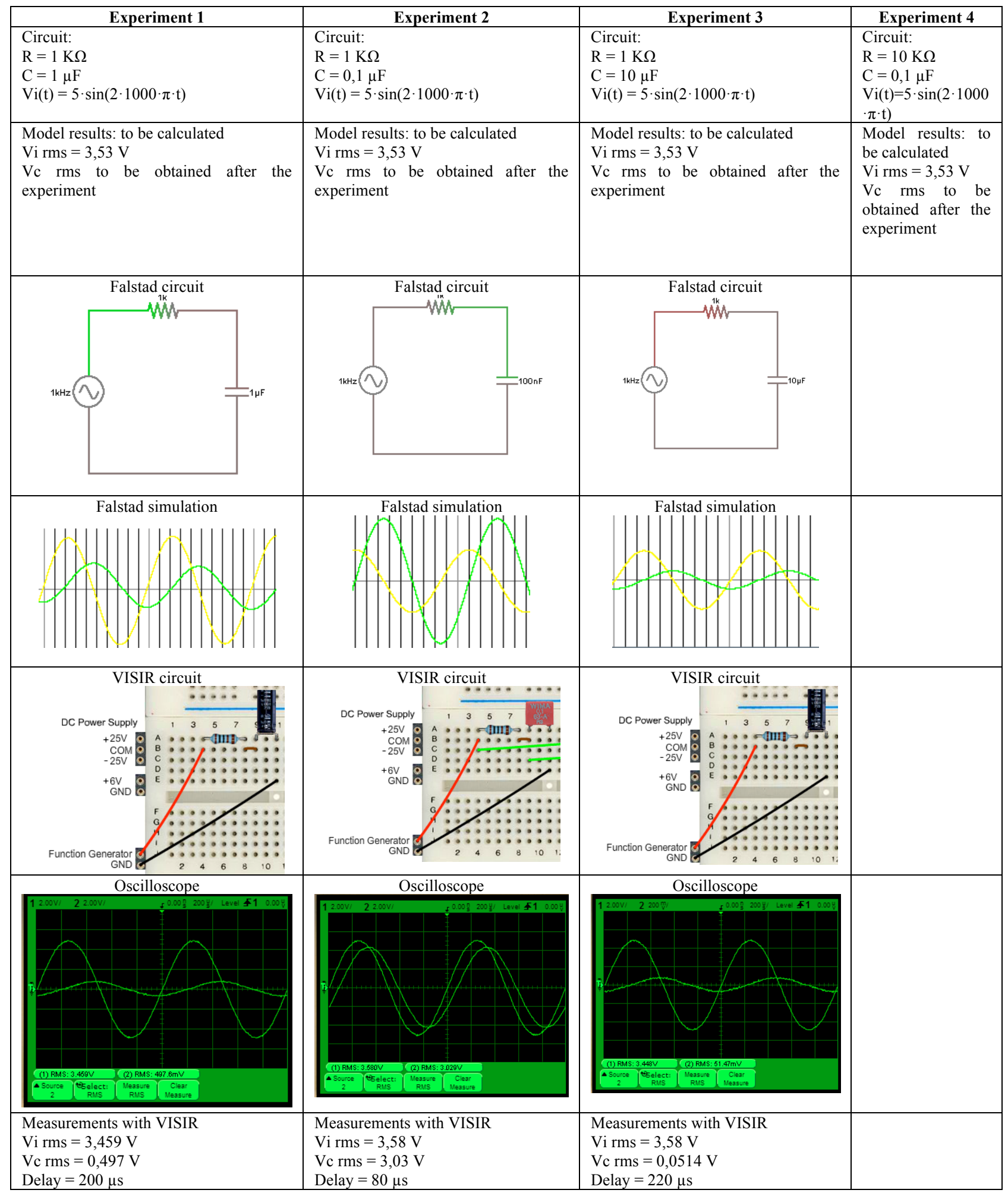




\section{Pedagogical Model}

The modules should be easily integrated in different pedagogical models. In Fig. 5 the popular constructivist model is shown, the blue lines draw the teaching/learning process.

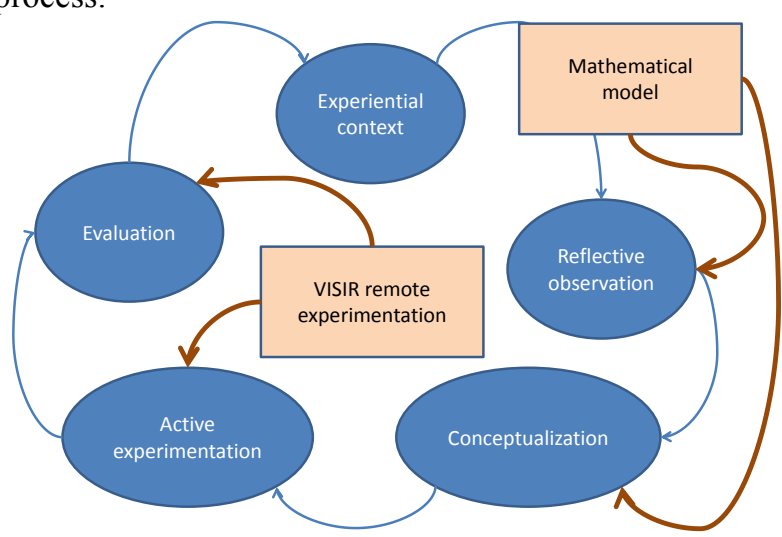

Figure 5. Constructivist model

In the inquiry learning model [8] of Fig. 6 a different approach of the teaching/learning process is shown, but also in this case the tools used in the modules can be adapted.

It is very important that every teacher can adapt easily the modules to the approach used by him/her or by the school.

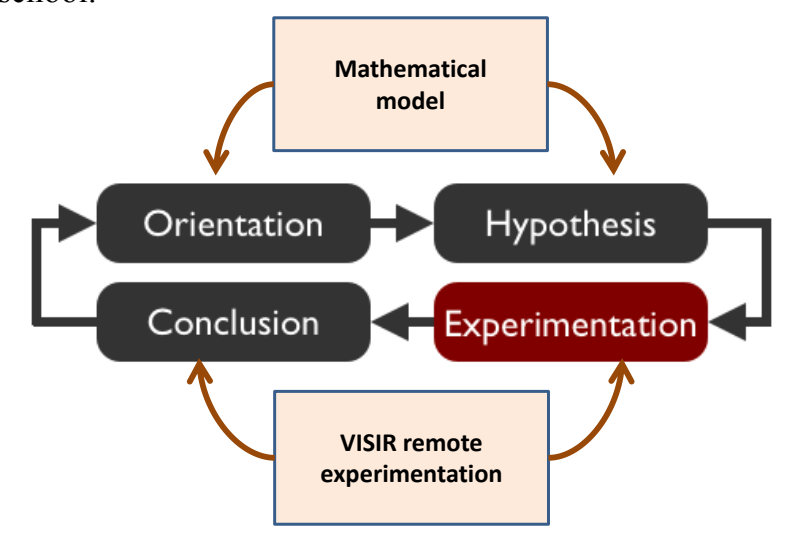

Figure 6. Inquiry learning model

Fig. 5 and Fig. 6 together with Table I and Table II follow the steps clockwise: circuit, mathematical model, simulation, results in simulation (when possible), experiment in VISIR, measurements in VISIR and conclusions. But in Table III the process is different, anticlockwise: circuit, simulation, results in simulation (when possible), experiment in VISIR, measurements in VISIR, results analysis, proposed mathematical model, and evaluation of the model with new experiments.

Beyond the pedagogical model, it is very important to remark that VISIR can be used in the classroom. Usually the teacher does not use experiments in the classroom because they are difficult to manage and to show to the students, the teachers prefer to use the blackboard and the mathematical models.

But VISIR allows the teacher to use the experiments to evaluate the mathematical models presented by him/her, or to discover what is the mathematical model connected to the shown experiments. Even more, the students can access the VISIR simultaneously with the teacher, and in this situation each student can freely create experiments and discover the models related with them.

This new scenario offers the teacher new possibilities to improve the teaching/learning process. The objective of OLAREX is not to exploit specifically these new possibilities, its objective is to open the new scenario.

\section{CONCLUSIONS}

The OLAREX project offers the STEM teachers and students modules and tools to improve their teaching/learning process using ICT.

To teach/learn STEM, experiments are very important, but it is difficult include them in a subject, especially in secondary school. This drawback can be solved using the remote experimentation offered by OLAREX.

Using remote labs, the students/teachers can access real experiments without effort, they only need an Internet connection. Different modules have been designed to promote and to help teachers and secondary schools in this process.

The people interested in OLAREX and the modules may contact the authors.

\section{REFERENCES}

[1] M. Gould, "Girls choosing camera lenses over microscopes", The Guardian. (Oct. 03, 2008), http://www.guardian.co.uk/education/ 2008/oct/03/science.choosingadegree (accessed March 12, 2012)

[2] www.olarex.eu

[3] www.olarex.edu/moodle/

[4] www.facebook.com/pages/Olarex-EU-Project

[5] www.weblab.deusto.es

[6] Gustavsson, I. et al. "On objectives of instructional laboratories, individual assessment, and use of collaborative remote laboratories", Trans. Learning Technologies, Vol. 2, No 4, pp: 263 -274, Oct-Dec 2009. http://dx.doi.org/10.1109/TLT.2009.42

[7] http://www.falstad.com/circuit/

[8] Jong, T. "Technological advances in Inquiry learning" Science, VOL 312, pp: $532-533$, April 2006.

\section{AUTHORS}

J. García-Zubía is with the University of Deusto, Bilbao (Spain). Avda. Universidades 24, Bilbao (Spain), (e-mail: zubia@deusto.es) .

Ignacio Angulo is with the University of Deusto, Bilbao (Spain). Avda. Universidades 24, Bilbao (Spain), (e-mail: Ignacio.angulo@deusto.es).

O. Dziabenko is with the Deusto Institute of Technology, Bilbao (Spain). Avda. Universidades 24, Bilbao (Spain), (e-mail: olga.dziabenko@deusto.es).

P. Orduña is with the Deusto Institute of Technology, Bilbao (Spain). Avda. Universidades 24, Bilbao (Spain), (e-mail: pablo.orduna@deusto.es).

No. 518987-LLP-1-2011-1-ES-KA3-KA3MP funded with support from the Lifelong Learning Programme (KA3 - ICT) from European Union. This article is an extended and modified version of a paper presented at the EDUCON2013 conference held at Technische Universität Berlin, Berlin, Germany from March 13-15, 2013. Submitted 04 June 2013. Published as re-submitted by the authors 11 October 2013. 